\title{
Colonialismo y violencia. Bases para una reflexión pos-colonial desde los derechos humanos
}

Colonialism and Violence. Foundations for a postcolonial reflection from a human rights perspective Colonialisme et violence. Quelques bases pour une réflexion post-coloniale à partir des droits humains

\section{Joaquín Herrera Flores}

\section{OpenEdition}

\section{Journals}

Edición electrónica

URL: https://journals.openedition.org/rccs/897

DOI: $10.4000 /$ rccs.897

ISSN: 2182-7435

\section{Editor}

Centro de Estudos Sociais da Universidade de Coimbra

Edición impresa

Fecha de publicación: 1 octubre 2006

Paginación: 21-40

ISSN: 0254-1106

\section{Referencia electrónica}

Joaquín Herrera Flores, «Colonialismo y violencia. Bases para una reflexión pos-colonial desde los derechos humanos», Revista Crítica de Ciências Sociais [En línea], 75 | 2006, Publicado el 01 octubre 2012, consultado el 21 septiembre 2021. URL: http://journals.openedition.org/rccs/897 ; DOI: https:// doi.org/10.4000/rccs.897 


\section{Colonialismo y violencia. Bases para una reflexión pos-colonial desde los derechos humanos}

Percorrem-se quatro mecanismos fundamentais do difusionismo colonialista ocidental: o estabelecimento de generalizações abusivas que impedem o conhecimento da complexidade do outro; o backlash colonialista e a ocultação das origens dos processos coloniais; a transformação do espaço geográfico; o humanismo abstracto e a sua distância no referente às práticas depredadoras do colonialismo. Estes mecanismos são analisados da perspectiva de uma concepção radical de direitos humanos, concluindo-se que a capacidade de lutar tanto pelo reconhecimento cultural como pela justa distribuição de recursos está na essência da afirmação desses direitos.

\section{Los cuatro mecanismos fundamentales del difusionismo "colonialista" occidental}

I.1. Establecimiento de generalizaciones abusivas que impiden conocer la complejidad del otro

Comencemos comentando las afirmaciones de Samuel P. Huntington en The Clash of Civilizations and the Remaking of World Order. El libro del asesor presidencial norteamericano ejemplifica la actitud que podemos denominar de antropoémica que rechaza sin matices al otro, que lo vomita, que lo desprecia. Huntington diseña un mapa de los conflictos actuales desde la perspectiva civilizatoria ${ }^{1}$ en el que muestra - sin los matices necesarios para comprender las diferentes percepciones de la complejidad del mundo contemporáneo -, lo que él denomina tres universalismos: el judeo-

\footnotetext{
${ }^{1}$ Al dejar de lado cualquier consideración acerca de las desigualdades económicas y sociales como bases de dichos conflictos contemporáneos (Huntington asume con plenitud las tesis del "fin de la historia" después de la "derrota" del comunismo real), el politólogo norteamericano no deja campo para una reflexión que indague sobre la responsabilidad de occidente y su expansionismo colonial por haber iniciado y potenciado tales desequilibrios favorables, como también vimos más arriba, a las diferentes fases de acumulación del capital. Como dijimos, tesis culturalistas como las de Huntington oscurecen, más que aclaran, el origen y el despliegue de los conflictos a los que tendremos que enfrentarnos en el siglo que comienza.
} 
cristiano $^{2}$, el islamista y el confuciano. Al no poder negar que estamos ante tres centros de "difusión" cultural con pretensiones de universalidad, el autor norteamericano nos advierte de los peligros que corre el modelo "cultural" occidental, frente al posible entendimiento y unidad de acción entre el Islam y el confucianismo para destruir la civilización cristiano-capitalista. Aparte del conjunto de generalizaciones "antropoémicas" que proliferan en todo el texto de Huntington y su "aparente" desconocimiento de la pluralidad y las fracturas que existen tanto en el ámbito del Islam como en el de los países de influencia confuciana, lo que destaca en el conjunto de sus argumentos es el miedo occidental de perder la hegemonía cultural-colonial en la que se han basado las diferentes expansiones imperiales que han signado durante más de cuatro siglos los diferentes procesos de la acumulación capitalista. ${ }^{3}$

Para nosotros, la cuestión reside en que tenemos que ser conscientes de que existe un arraigado y perverso paradigma cultural en el marco de las sociedades occidentales en su relación con los otros, especialmente las sociedades árabes y musulmanas. Este paradigma se sostiene básicamente en criterios esencialistas que parten de una concepción a priori del resto de culturas. Así, todo producto cultural islámico "tiene que ver" con la religión; África se visualiza desde la etnicidad; Asia, como ejemplo de pasividad; y los pueblos indígenas sólo son visibles como folklore. Todo ello nos induce a una percepción monolítica y estática de los procesos culturales interiorizados por el punto de vista colonial y difusor: los otros son vistos como culturas cerradas, inmodificables en sus aspectos fundamentales, portadoras de tradicionalismos inmutables y agresivos. De ese modo, toda "diversidad cultural" es interiorizada en nuestras conciencias desde una perspectiva

\footnotetext{
2 Sin aclarar taxativamente lo que se entiende por "judeocristianismo" (dadas las relaciones históricas conflictivas que los dos términos del concepto han mantenido y su propia ambigüedad categorial expresada en la calificación de "oriental" que desde el cristianismo siempre se ha vertido sobre lo judío), el término ha adquirido fama por su importante rol a la hora de diferenciarnos "en bloque" de todo lo islámico y lo confuciano. "El mundo se divide en las 'culturas judeocristianas' y las otras", se dice, nada más y nada menos que en el Cuarto Informe sobre el proceso de organización de la Alianza por un Mundo Responsable y Solidario (sic) auspiciado por la Fundación Charles Lépold Meyer por el Progreso del Hombre, París, 1998. Cfr. Bessis, 2002: 269; asimismo, y desde la perspectiva de las "razonables" reticencias árabes frente a lo judío, cfr. Martín Muñoz, 1999. Sería interesante constatar la real proximidad y las diferencias concretas entre las tres religiones implicadas en esta problemática. Ver, entre otros, Arnaldez, 1991; y Benslama, 1998.

${ }^{3}$ Nunca nos cansaremos de advertir sobre los peligros del culturalismo: en el caso de Huntington, hay que repetir que no puede haber conflictos culturales desgajados de sus bases económicas y contextos sociales y políticos; por lo tanto, no puede haber colonialismo cultural al margen de los colonialismos políticos, sociales y económicos. Aquél sólo legitimará la aventura colonial o un tipo de oposición sesgada a favor de las elites autóctonas. Recuérde el texto publicado en Marzo de 2004 en Foreign Policy y que comentamos más arriba.
} 
negativa provocándonos una fuerte ceguera ante los intentos democratizadores que se llevan dando en el mundo árabe desde hace decenios. Como afirma la profesora Gemma Martín Muñoz,

A nosotros nos repugna todo lo negativo que hay en el mundo musulmán (tanto) desde nuestras posiciones esencialistas, que no quieren ver lo que realmente pasa allí y prefieren seguir pensando que es un mundo monolítico, retrasado y sin capacidad de transformación, (como) etnocéntricas, porque nos permiten proclamarnos en los representantes universales de la civilización, cuando en realidad estamos contribuyendo a que la democracia, la libertad y el estado de derecho no se desarrollen en esta parte del mundo. (Martín Muñoz, 2004) ${ }^{4}$

Pero al "centro colonial difusor" le interesa más volver la espalda a las realidades concretas, consolidar estereotipos culturalistas que obvien las causas reales de los llamados fundamentalismos (como reacción poscolonial de países antaño colonizados) e implantar - al estilo de Huntington, el cual podría haber sido perfectamente entrevistado en Bowling for Columbineel horror ante el diferente esencializado en categorías que justifican nuestro rechazo.

Desde el "miedo", difícilmente pueden comprenderse los fenómenos culturales. Aparte de tener que repetir que no pueden darse colonialismos culturales sin colonialismos económicos y políticos, lo que nos interesa destacar en este momento, es que a partir del miedo lo único que se hace es generalizar al "enemigo" como alguien que se opone, también sin fisuras y sin matices, a nuestra forma de vida. Si todas las entidades culturales están cerradas al exterior y son monolíticas en su interior, la hipotética enemistad u oposición termina eternizándose y pudriéndose en sí misma ante los obstáculos infranqueables para la comunicación y el diálogo intercultural.

Por lo tanto, cabría preguntar, dado el éxito de estas propuestas ¿cuáles son los mecanismos de este mecanismo de difusión "colonialista"? ¿Qué es lo que se pretende: advertir de los peligros de la hipotética lucha entre civilizaciones o, por el contrario, provocar tales peligros con el objetivo final de ocultar los conflictos reales y los intereses geoestratégicos que subyacen a los procesos culturales hegemónicos?5

\footnotetext{
${ }^{4}$ Cfr. asimismo Martín Muñoz, 1999, esp. 289-321.

${ }^{5}$ Las dudas acerca de la autoría de los atentados del 11 de Septiembre - los cuales están siendo usados para legitimar el odio racial y la consiguiente supresión de libertades individuales en todo nuestro mundo -, crecen cada vez más. Lo que parece estar demostrado, y nadie lo deniega públicamente, es que los terroristas no pudieron actuar en soledad e, incluso, que el choque de los aviones contra las Twin Towers no pude por si mismo causar tamaña destrucción y pérdida de vidas humanas. Ver Meyssan, 2002 (consultable, asimismo, en www.effroyable-imposture.net)
} 


\section{I.2. El backlash colonialista o la ocultación de los orígenes de los procesos coloniales}

Toda acción, tarde o temprano, encuentra su reacción. Las luchas llevadas a cabo en los años sesenta y setenta del siglo pasado se llevaron a la práctica complementando el deseo de libertad personal con la crítica radical del capitalismo, ya que éste se veía como la forma hegemónica de relación social impulsora de toda explotación y de todo colonialismo. Sin embargo, llegaron los años ochenta y, con ellos, la reacción de la llamada "nueva filosofía" - basada en lo que se designó como el "pensamiento débil" dado su abandono de la relación entre la reflexión intelectual y la política-, y la "nueva sociología" - para la que los conflictos sociales habían dejado de tener causas estructurales, es decir, económicas y geoestratégicas, y pasaban a ser vistos como problemas de la sociedad de la información y del riesgo.

Entre los que destacan en ese triste conjunto de "pensadores", tenemos, en primer lugar, la figura de un Pascal Bruckner y sus esfuerzos por desculpabilizar y desresponsabilizar al "hombre blanco" por el genocidio colonialista en su libro Le sanglot de l'bomme blanc publicado en 2002; y, en segundo lugar, a André Glucksmann, el cual, en un texto publicado El País en febrero de 1998, afirmó que la violencia que asola a muchos países musulmanes no tiene orígenes estructurales (es decir, socio-económicos), sino que es producto de una desviación patológica de tipo religioso-islámico que los distingue "inexorablemente" del resto del mundo civilizado. Aún más radicales son las páginas del primer volumen que la editorial Denoël consagró a L'Aventure coloniale de la France, que se llamó L’Empire triomphant (1871-1936), donde, "a mediados de los años noventa" del siglo XX, se hacía una apología directa de la aventura colonial francesa como una epopeya digna de encomio, sin tomar en consideración el rastro de muertes, torturas y subdesarrollo que dejaron las políticas coloniales y sus secuelas de violencia y migraciones en masa que hoy vemos cotidianamente por las pantallas de televisión.

Estamos ante un "backlash", o lo que es lo mismo, ante la típica reacción negativa contra determinadas tendencias sociales, económicas o culturales que no nos interesa visibilizar, pues desenmascararían nuestra inserción histórica o política en un universo cultural contrario a los intereses del momento. Con este tipo de reacción, muy extendida en Europa desde los

(consultada en septiembre 2003); Klein, 2002; Hufschmid, 2002. Asimismo, las siguientes páginas web: www.rense.com, www.whatreallyhappened.com, www.americanfreepress.net, www.public-action.com. Asimismo, no dejar de leer el detalladísimo informe de Lluís Botinas i Montell, publicado en la revista El Viejo Topo (Montell, 2003). 
inicios del Renacimiento - y contra las que ya el historiador Herodoto se enfrentó en su tiempo -, lo que se intenta es fundamentalmente dos cosas. En primer lugar, construir un tipo de identidad abstracta que no se apoya en orígenes históricos y políticos concretos. Es decir, un tipo de identidad vacía de influencias foráneas y apoyada en algún tipo de mitología originaria no susceptible de ser racionalizada y contextualizada. Recuérdense los múltiples procesos de "limpieza de sangre" que pueblan nuestra historia occidental y la importancia que tuvieron a la hora de incluir a unos y excluir a otros. Téngase asimismo en cuenta la barbarie cultural que se dio en los Balcanes con el objetivo de borrar cualquier conexión entre el Cristianismo, el Judaísmo y el Islam. Barbarie, que tuvo como consecuencia la destrucción inmediata y planificada de la Biblioteca de Sarajevo: lugar de encuentro documental de las tres religiones del libro. Y, en segundo lugar, si no logramos ocultar los orígenes interculturales de nuestra identidad o somos conscientes de hechos concretos que no nos es posible negar (por ejemplo, la traducción árabe de los libros de la Grecia clásica), se "inventan" orígenes identitarios que no se contrapongan a los intereses y miedos del presente (véanse, como ejemplos los tradicionales intentos por separarse de la innegable influencia islámica en la Europa medieval, entre los que destaca la búsqueda del "santo grial" como la reliquia que nos identifica como cristianos puros; el invento de la figura de "Santiago matamoros"; las recurrentes expulsiones de judíos; las prácticas inquisitoriales, la invisibilización de la influencia del Egipto Negro en la filosofía grecorromana, etc.).

Tanto desde una tendencia como desde la otra, primero, se niegan las raíces interculturales de todo proceso cultural; $y$, segundo, se ocultan determinados hechos históricos que nos podían hacer depender de tradiciones que queremos expulsar de nuestro inconsciente colectivo. Siendo la justificación última de todo este procedimiento de backlash, la de mostrar la "inevitabilidad" histórica de la superioridad del centro colonial difusor. Desde dicho proceso de ocultación de la memoria histórica podemos entender el esfuerzo de los pensadores renacentistas por "invisibilizar" las múltiples deudas que Europa tenía con el mundo árabe, para, acto seguido, afirmar nuestras raíces grecorromanas; o el esfuerzo de historiadores de prestigio por negar los orígenes lidios de la civilización romana: ¿cómo pensar que Roma, la continuadora de la cultura etrusca, hundía sus raíces en la bárbara Asia Menor, actual Turquía? Como afirma Sophie Bessis, y ampliaremos más adelante, con este procedimiento lo que en última instancia se pretende es borrar “...las influencias babilónicas, caldeas, egipcias e indias de Grecia... (ignorar) el inmenso prestigio que tuvo Egipto 
en el mundo griego... (silenciar) la pluralidad cultural del Imperio romano... (y junto a) la expulsión física del Islam del territorio político de Europa occidental (expulsar, asimismo) el pensamiento judeo-musulmán del territorio intelectual europeo".

Ahora bien, este mecanismo de "backlash", tiene una vertiente aún más perversa. Al idealizar una cultura, extirparle sus orígenes interculturales e "inventarle" una tradición que poco o nada tiene que ver con sus vecinos, se va despejando el camino para la intervención de la cultura superior sobre las que se consideran inferiores y, sobre todo, ajenas. Todo expansionismo colonial queda, pues, justificado e idealizado. Y si se han realizado determinados actos violentos de conquista y dominación, todo queda legitimado por los objetivos de la empresa civilizadora. África, la gran ausente, por invisibilización cultural, de nuestras tradiciones renacentistas e ilustradas, es considerada por algunos como corresponsable del fenómeno de la esclavitud, dada la colaboración con los esclavistas de algunos reinos y etnias del continente. La violencia colonial se justifica gracias a la "inevitable" crueldad humana, siendo los actos de los esclavistas ni menos perversos ni menos injustos que los de sus colaboradores negros (¿se preguntan éstos cuál fue la razón de que Europa se enriqueciera con el esclavismo y, sin embargo, África quedara sumida en la más atroz de las miserias?). Y, además, el "backlash" desculpabilizador de Europa parte de otra línea de pensamiento: es posible que las empresas coloniales produjeran destrozos y quebrantos en los pueblos colonizados, eso lo aceptamos; pero, al mismo tiempo, hemos sido los únicos - y lo seguimos haciendo al parecer en Irak o en el actual Líbano - que, tras la destrucción, estamos capacitados para enviar todo un aparato "humanitario" que se dedique a "curar" las heridas más visibles de nuestras acciones ¿Cómo explicar entonces las revueltas y las reacciones, asimismo, violentas de quienes son objeto de tales intervenciones humanitarias? ¿Son unos desagradecidos o, en realidad, protestan ante una ocupación que ellos nunca pidieron? Destrucción y reconstrucción. Estamos como aquellos indígenas amazónicos o aquellos esquimales canadienses que a causa de las continuas invasiones de sus territorios por occidentales cayeron enfermos de males hasta entonces desconocidos por sus chamanes. A partir de ahí de nada valían los conocimientos tradicionales; sólo podían curarse acudiendo a la medicina y a los hospitales de aquellos que les habían introducido la enfermedad. ¿No es el "backlash" la enfermedad y el remedio? ¿Realmente el remedio curará la enfermedad o provocará males de mayores proporciones, como, por ejemplo, la aculturación, la migración forzada a los "centros culturales", la marginación, la delincuencia, la drogadicción...? 


\section{I.3. La transformación del espacio geográfico}

Leamos a Edward Said:

Después de todo, el imperialismo es un acto de violencia geográfica por medio del cual, virtualmente, cualquier espacio del globo es explorado, cartografiado y finalmente sometido a control. Para el nativo, la historia de la servidumbre colonial comienza con la pérdida del lugar a favor del extraño. (Said, 1996: 349)6

Como Don Quijote en su primera salida al mundo, Colón, y tras él el resto de aventureros europeos que se lanzaban a lo, para ellos, desconocido y misterioso, lo primero que iba haciendo era poner nombres a los lugares a los que llegaba. Las islas del actual Caribe ya no iban a ser nombradas con sus nombres tradicionales sino con los que el conquistador iba imponiendo para mayor gloria de los monarcas que financiaban sus empresas. Pero no se conformaban con esto. El cambio de nombre llevaba implícito la transformación del hábitat local con el objetivo, consciente o inconsciente, de convertir los territorios conquistados, muchos de ellos hostiles a las características del hombre blanco europeo, en espacios familiares, en imágenes de los lugares que había abandonado. Ante la mirada atónita de los indígenas, todo un arsenal de máquinas y técnicas se usaban para reconvertir el espacio conquistado en un lugar inédito para los que habían vivido ancestralmente en él.

Pero ahí no quedaba la cosa. A medida que se reconstruía el espacio geográfico, se iba reconstruyendo de un modo radical el sistema de relaciones frente al que los indígenas habían reaccionado culturalmente a lo largo de sus historias. Ejemplo de ello lo encontramos en las políticas coloniales de las metrópolis dirigidas a modificar las prácticas y formas de percibir y trabajar los territorios que ocupaban en función de un tipo de producción ajeno al que tradicionalmente se había llevado a la práctica. La producción intensiva de productos exigidos por las metrópolis, obligaron a una reestructuración del territorio de tintes marcadamente imperialistas: grandes posesiones, introducción de técnicas adecuadas para los monocultivos, desaparición de conocimientos tradicionales mucho más apegados a la regeneración de la tierra que a su explotación intensiva... Todas estas prácticas coloniales supusieron, entre otros fenómenos, una transformación de la naturaleza y del espacio de lugares, muchos de ellos considerados sagrados,

\footnotetext{
${ }^{6}$ Ver, como referencia de los argumentos que siguen, los siguientes textos que desarrollan las tesis esgrimidas por el propio Said, las cuales están en la base de nuestra argumentación: Cosby, 1986: 196-216; Smith, 1984: 100 y ss; Hamer, 1989.
} 
en "bienes" a explotar bajo la égida del centro metropolitano. En este sentido, es interesante el desarrollo a fines del siglo XIX y principios del XX de una geografía comercial que clasificaba los territorios en función de las necesidades de los países colonizadores y de su sistema económico, el capitalismo, cuya forma de diferenciación territorial ha estado siempre relacionada con la división social del trabajo y el aumento de la productividad, y, muy poco, con las formas tradicionales de percibir, interpretar e intervenir en el mundo.

Asimismo, en este proceso de producción imperialista y "difusionista" del espacio, se exigía la implantación en los territorios conquistados de las mismas reglas jurídicas que primaban en la organización espacial en las metrópolis. Ejemplo de ello lo encontramos en los tristemente famosos "decretos de registro" que los ingleses aplicaron indiscriminadamente en la Irlanda del primer tercio del siglo XIX. A partir de estos "registros" se "anglizaban" los nombres de los lugares, se redefinían las lindes con el objetivo de facilitar la valoración económica y el registro mercantil de las tierras expropiadas y se derogaban los textos jurídicos que habían regulado el intercambio patrimonial. ¿Cómo dejar que sea el colonizado quien controle su propia representación geográfica y jurídica? Mejor que esa utópica actitud, está la de homogeneizarlo jurídicamente y someterlo, dada su "pasividad" y su "pereza" innatas, a las normas y valores que primaban en la metrópolis. ¿Qué otra cosa se hizo en la India, en Argelia, en la repartición de África a finales del siglo XIX, en la labor de aculturación llevada a cabo por los conquistadores españoles en las sierras andinas, en la "epopeya" de la conquista del oeste norteamericana o, por terminar por algún lado, en la expansión anglosajona por toda Oceanía?

En su novela Baudolino, Umberto Eco nos advierte de la relatividad y la dependencia ideológica de los mapas con respecto a quien tiene el poder de representar el mundo desde sus intereses y expectativas. Con su habitual maestría literaria, Umberto Eco utiliza la creencia medieval en la existencia del mítico reino cristiano del Preste Juan ${ }^{7}$, con el objetivo de comunicarnos

\footnotetext{
${ }^{7}$ La leyenda del Preste Juan es muy sintomática del horror occidental-cristiano ante los avances del "gran otro", del Islam (base, como estamos viendo, de las actuales ideologías del "choque entre civilizaciones"). Tras la prohibición del cristianismo y del budismo en la China del siglo IX, todos los intentos de universalizar la religión cristiana parecieron terminar. Sin embargo, tanto en el Imperio Romano Oriental como en el Vaticano, esta constatación no podía aceptarse en su plenitud dada la tendencia universal de sus presupuestos ideológico-religiosos. Para ello, se divulgó la idea de que en el Extremo Oriente existía un poderoso rey sacerdote cristiano (el llamado "Preste Juan de las Indias") que estaba preparado para reestablecer contacto con las autoridades religiosas cristianas y el mundo occidental, con el objetivo de fundar universalmente el reino de dios en la tierra. En el fondo - nos cuenta Herbert Wendt - la esperanza en el Preste Juan no era otra cosa que un deseo fantasmagórico de la cristiandad de tener un aliado poderoso (por supuesto, imaginario,
} 
esa relatividad y ese carácter ideológico de las representaciones geográficas. Como dice Zósimo, uno de los personajes centrales de la novela, a Baudolino (en el momento en que ambos están pergeñando una treta para que el gran Federico Barbarroja dedique fondos y atención a la leyenda que ellos mismos han venido construyendo acerca del Preste Juan), la construcción del espacio tiene mucho que ver con quién tiene el poder para realizarlo.

Por otra parte [dice Zósimo a un Baudolino incrédulo, pero decidido a seguir engañando al Barbarroja], me han dicho que los sarracenos dibujan mapas donde el mediodía está arriba y el septentrión abajo y, por lo tanto, el sol nace a la izquierda de las tierras que "representan". Si tú aceptas mi manera de representar el curso del sol y la forma de la tierra, siguiendo mis indicaciones llegarás seguramente a donde yo te quiero enviar, mientras que no sabrás entenderlas si las refieres a tus mapas. Así pues - concluyó triunfalmente Zoísmo -, si quieres alcanzar la tierra del Preste Juan, tienes que usar el mapa del mundo que el Preste Juan usaría, y no el tuyo, fíjate bien, "aunque el tuyo sea más correcto que el suyo".

\subsection{El humanismo abstracto: la distancia entre el discurso humanizador y las prácticas depredadoras del difusionismo colonialista}

Desde la polémica renacentista sobre si los indios del Nuevo Mundo eran o no seres humanos a principios del siglo XVI, hasta la proclamación del "eje del mal" por parte de las autoridades norteamericanas en su justificación ideológica de la guerra contra Irak a inicios del siglo XXI, Occidente se ha abrogado el derecho de, por un lado, ser el portador de las ideas universales de justicia y dignidad que se formulan en la modernidad, y, por otro, de obstaculizar cualquier proceso modernizador que los pueblos colonizados han intentado llevar a la práctica sin renunciar a sus principios y sus propuestas culturales. Occidente y sus valores, se nos repite constantemente, constituyen los ítems fundamentales de la modernidad. Cualquier intento de salir de las tradiciones desde otros valores y otros procedimientos distintos de los occidentales, es calificado inmediatamente de antimoderno, y, por ello mismo, susceptible de ser "intervenido" quirúrgicamente para extirpar el virus dañino que induce a los otros a no querer ser exactamente iguales a nosotros. Estamos ante lo que podemos denominar como el "efecto

pero de gran poder simbólico) contra la fuerza del Islam. Estas fantasías políticas situaron al Preste Juan en diferentes lugares (India, China, Abisinia) en función de los intereses en la lucha militar y cultural contra los musulmanes. Hacia mediados del siglo XII se supo que en algún lugar de Oriente un soberano desconocido había vencido a los musulmanes... no podía ser otro que el Preste Juan (aunque en realidad, se trataba de Yi-hu-ta-shi, cabecilla del pueblo nómada de los mogoles que tanta importancia adquirieron después en los miedos occidentales ante los bárbaros asiáticos, al casi dominar media Europa en pleno siglo XIII, bajo el mando de Gengis Kan). 
espejo" de la ideología legitimadora del difusionismo colonialista occidental, la cual consiste en buscar sistemáticamente en las otras sociedades los símbolos y las prácticas que nos devuelven nuestra propia imagen. De un modo u otro, sólo dialogamos con nosotros mismos ante el espejo que nos refleja, y si no hay otro remedio que buscar interlocutores válidos, éstos serán aquellos que sean nuestros dobles: el buen islámico, el buen negro, el buen asiático... Todos aquellos que se distancian de dicha imagen, no sólo se les reniega como interlocutores, sino que se les impide construir los mecanismos para poder, en su caso, llegar a serlo. Un ejemplo paradigmático de lo que decimos son los argumentos de David Pryce-Jones (1988). Para este autor, la expresión "demócrata árabe" es una "contradicción en los términos". Pryce-Jones demuestra una tremenda ignorancia de los procesos democratizadores desplegados por el mundo árabe desde el siglo XIX hasta la actualidad (la experiencia tunecina de Jayr al-Din en 1861; la de Muhammad 'Ali en el Egipto de 1830 que desembocó en el proyecto constitucional democrático de 1879; el intento democratizador de Muley Hafiz en el Marruecos de inicios del siglo XX, etc. [Martín Muñoz, 2001]). El mundo musulmán nada tiene que ver con el mundo democrático. De tal modo que el continuo bloqueo de esos procesos democratizadores por parte de las potencias occidentales haya quedado sepultado en el olvido. El silogismo del difusionismo colonialista es absolutamente perverso: si tales países son ontológica y esencialmente incapaces de ser democráticos, está legitimada la intervención para interrumpir la "democratización” de los mismos, dado que sólo se llegaría a aberraciones antioccidentales, y, por ello mismo, irracionales, bárbaras, salvajes y primitivas. De este modo, se ocultan e invisibilizan las causas históricas que han dado lugar a la violencia integrista (no reducible a lo islamista) en Egipto o Argelia, impidiendo cualquier tipo de investigación seria y neutral que muestre al público la verdadera responsabilidad de tal violencia. ¿Podemos olvidar el apoyo occidental a grupúsculos integristas enemigos de toda reforma modernizadora de sus países, por ejemplo durante el gobierno de Nasser en Egipto, los taliban en Afganistán o en el mismo Pakistán, tradicional aliado anticomunista de los Estados Unidos de Norteamérica? ¿Debemos considerar como dato que explica la seducción islamista, el hecho de que en los países musulmanes 3 de cada 4 jóvenes sufre un desempleo crónico sin muchas posibilidades de solución? ¿O este dato no tiene nada que ver con la pretendida colisión de civilizaciones?...

"La paradoja de occidente reside en su facultad de producir universales, elevarlos al rango de lo absoluto, violar con un fascinante espíritu sistemático los principios que de ellos derivan y elaborar las justificaciones teóricas 
de estas violaciones" (Bessis, 2002: 19). Es decir, el humanismo abstracto occidental funciona de la siguiente manera: primero, se apropia del proceso de humanización que en todo espacio cultural se ha dado y se ha intentado plasmar política, social y normativamente; segundo, ante la necesidad de ocultar tal apropiación ilegítima, eleva sus principios a la categoría de absolutos y abstractos, es decir, los "abstrae" de los contextos interactivos en los que han surgido; $y$, tercero, establece una distancia inabarcable entre el discurso humanizador y las prácticas deshumanizadoras funcionales a sus intereses geoestratégicos.

Esta triple actuación, como decimos, es perfectamente funcional a las diferentes fases del proceso de acumulación capitalista pues justifica la necesidad de expansión global del mismo. Así, se nos induce, primero, a considerar todo lo bueno como lo nuestro - lo universal bumanizador - y "exportar" en bloque todo lo que rechazamos de nosotros mismos a los otros - que siempre actúan violando dicho universal - (sea a través de la presencia continua de las justificaciones religiosas, de la crueldad a la que somos tan proclives, o de las tendencias latentes a renovados tipos de autoritarismos y totalitarismos) En segundo lugar, se nos propone reconocer la diversidad cultural e, incluso, reivindicar las ventajas del multiculturalismo, pero, sin hacer dejación de nuestra superioridad como centro difusor de todo lo que se entiende por cultural o civilizado - elaboración de la justificación de la violación del universal bumanizador. Y, en tercer lugar, siendo ésta la consecuencia de los dos elementos anteriores, construir una tolerancia hacia el diferente en el interior de nuestro espejo. Con ello se consigue demonizar y excluir a los diferentes, a los otros, a los ajenos, a los que no aparecen en la imagen especular que de nosotros tenemos, justificando expresamente todo tipo de colonialismos, etnocentrismos e imperialismos - la intervención colonial como necesidad histórica.

Todas estas "herramientas" teórico-ideológico-políticas que renuevan constantemente las bases de la supremacía con la que se reviste el centro difusor, son el principal obstáculo para lograr una reestructuración de las relaciones mundiales basada en la interacción entre todas las formas de vida y, consecuentemente, entre todas las formas de reacción cultural - no sólo en la occidental -, que se han ido construyendo a lo largo de la historia. "Todo ello - afirma la profesora Martín Muñoz - nos lleva a constatar que el discurso sobre la amenaza islámica o el conflicto civilizacional Islam-Occidente es la pared de humo tras la que se ocultan los efectos de la legitimación e imposición de la supremacía cultural de Occidente; unido a la contradicción que supone pretender asumir en exclusiva la misión huma- 
nista universal y, a la vez, actuar en contra de la misma fuera de sus fronteras occidentales por intereses estratégicos o económicos de poder" (Martín Muñoz, 2002).

\section{I.5. La esencial "inconvertibilidad" del otro: Esperando a Godot no se consigue nada}

En 1953 se estrena en París la obra Esperando a Godot, salida de la pluma de un autor, por entonces un perfecto desconocido, llamado Samuel Beckett. En la pieza teatral, cinco personajes giran sobre la ausencia de un sexto - Godoy - que, por alguna razón u otra, nunca llega. Estragón, Vladimir, Pozzo, Lucky y el Muchacho mensajero de Godot, intentan insatisfactoriamente establecer algún lazo comunicativo que les permita entenderse y comprenderse en un mundo donde la tragedia se ha cernido alrededor de dos sangrientas guerras mundiales que enfrentaron a las potencias occidentales entre sí por causas geo-estratégicas, y la amenaza de una tercera, denominada fría, que parece va a ser la definitiva.

En Esperando a Godot, Samuel Beckett nos mostró la irracionalidad de un espacio cultural-colonialista como el europeo que no pudo ofrecernos claves para reaccionar frente al dolor, la explotación y la degradación humanas que se sufrió durante la primera mitad del siglo XX. Estragón, Vladimir, el hermano del Muchacho que advierte que Godot no vendrá nunca, y, Lucky, el Afortunado, aquel ¿ser humano? que tiene "la suerte" de ser explotado salvajemente por un Amo ciego que, sin embargo, depende absolutamente de él, son personajes arquetípicos que definen una época de barbarie bélica y sumisión colonial nunca experimentada hasta entonces. Aunque la obra de Samuel Beckett se ha interpretado como la expresión más pura de un nihilismo explícito pasivo, ${ }^{8}$ muy cercano a las caracterizaciones pesimistas acerca de la naturaleza humana que proliferaron en la primera mitad del siglo XX, nosotros, vemos en la obra del Premio Nóbel irlandés una crítica mucho más profunda a la situación por la que atravesaba la humanidad tras la segunda gran guerra. Pensamos que Beckett dirigía sus pullas críticas y amargas no sólo contra el humanismo abstracto que nada pudo hacer para evitar Auschwitz o las dos guerras mundiales, sino también contra un sistema económico e ideológico que secuestraba la posi-

\footnotetext{
${ }^{8}$ Siguiendo a Nietzsche, hay que distinguir, en primer lugar, entre dos tipos de nihilismos: el implícito, o sea, el que ni siquiera sabe que lo es; y el explícito: el que sabe que niega el estado de cosas dominante. Este nihilismo explícito se subdivide en dos tendencias: el pasivo, que niega pero no hace nada por actuar en consecuencia, y el activo, que niega, pero aportando alternativas de acción. La obra de Beckett se ha situado en el nivel del nihilismo explícito pasivo, pues parece que los personajes se debaten en la absoluta imposibilidad del movimiento y la acción.
} 
bilidad de hacer que las personas tienen como base de su dignidad. Los personajes de Beckett, tienen secuestradas sus capacidades y sus potencialidades para actuar, se hallan encerrados o enterrados en montones de detritus y basuras ya que han sido profundamente escindidos entre lo que son como seres humanos - seres productivos y activos - y lo que son como seres explotados por un sistema económico y de relaciones supeditado al capital que le expropia la base de su naturaleza humana - el hacer y la relación directa con los productos de su hacer.

Beckett escribe para la humanidad, no sólo en la medida en que nos muestra una naturaleza humana perdida en los vericuetos de caminos sin objetivo y sin salida, sino, de un modo muy especial, al mostrar los obstáculos morales, económicos y políticos infranqueables para individuos solitarios que esperan y esperan la llegada de un salvador que los saque de su situación de miseria y falta de reconocimiento. Beckett nos permite, en primer lugar, simbolizar a través de sus personajes las dificultades y obstáculos que encuentran los seres humanos para poder moverse y actuar en un mundo sometido al horror de la violencia bélica y de la soledad que surge como consecuencia de la pérdida de la colectividad. En segundo lugar, Beckett nos pone delante de todos aquellos que han sido sometidos a un proceso de colonización depredador que les ha impedido crear las condiciones adecuadas para la satisfacción de sus necesidades al hacerlos depender absolutamente de un poder cuasi-místico que nadie comprende, que nunca llega, pero que está en la base de muchas esperanzas humanas de emancipación. Y, en tercer lugar, lo que culturalmente es gravísimo, los personajes de Beckett representan a todos aquellos a los que se ha impedido que se les reconozca precisamente como seres humanos al negarles las mismas capacidades y potencialidades humanas que tenemos todas y todos a la hora de hacer y des-hacer los mundos en los que nos ha tocado vivir.

Pozzo - el salvaje Amo de Lucky -, pide a Estragón y a Vladimir que se identifiquen como seres humanos, ya que tiene necesidad de hablar con alguien que comparta su naturaleza, pues, Lucky, el dominado, ni siquiera puede hablar con sentido. Aunque Pozzo siempre dudará que aquellos dos desarrapados sean sus iguales, no tiene otro remedio que aparentar reconocerlos, aunque lo haga temporal y parcialmente, con el objetivo interesado de satisfacer su necesidad de auto-identificación como un poderoso propietario de sí mismo y de los bienes que le proporcionan bienestar. La supremacía de Pozzo, incluso padeciendo la ceguera del dominador, le viene por la creencia, compartida tanto por él como por su súbdito, en su innata superioridad, la cual le dota "por naturaleza" del privilegio de poder golpear y ser obedecido ciegamente por su esclavo. Tal como entra en escena, se va, 
dejando el mismo rastro de horror, de barbarie y de falta de reconocimiento del resto de seres humanos que se padecía en la época para la cual fue escrita la obra: una época, como decimos, lastrada por dos conflagraciones mundiales de índole imperialista y por el inicio de unos procesos de descolonización absolutamente controlados por las antiguas y nuevas metrópolis. "La prueba" - dice Estragón - "es que no nos ha(n) reconocido". Vladimir le replica: "Eso no quiere decir nada. Yo también he fingido no reconocerlo(s)... Además, a nosotros jamás nos reconoce alguien."

Toda la tragicomedia de Beckett gira sobre las consecuencias humanas que produce la falta de reconocimiento del otro y su marginación de los bienes que permiten vivir con dignidad, es decir, vivir con la cabeza levantada exigiendo y luchando por la satisfacción de sus necesidades humanas. Al excluido, al oprimido, al marginado de la riqueza social, sólo le queda esperar pasivamente y suplicar anhelante que algún día lo vean, le reconozcan su humanidad y le otorguen los bienes que los dominadores estén dispuestos a ofrecerles:

“¿Ya no tenemos derechos?” - se preguntan los dos desolados personajes - "Me harías reír, si me estuviera permitido... ¿Los hemos perdido?... Los hemos vendido."

Y, como consecuencia, el excluido, el marginado, el pobre, sólo es "visto" e identificado por sus rasgos físicos y naturales, no por las circunstancias que los han conducido a la situación que sufren. La exclusión se basa en el color, la raza, el rostro, los genes... y no se tiene en cuenta su naturaleza de animal cultural con capacidad universal de transformar su entorno y sus relaciones con el objetivo de alcanzar la dignidad necesaria para vivir. Por supuesto, Samuel Beckett no nos habla de raza, de color, y, mucho menos, de genes; pero hace que sus personajes no puedan de ninguna de las maneras deshacerse de sus harapos, de sus sombreros aplastados ni de sus rotos zapatos. Impotentes y encerrados en unas "ropajes" que los identifican ontológicamente sin posibilidad de "error", dialogan del siguiente modo: "No se puede hacer nada... Es inútil esforzarse... Uno sigue siendo lo que es... Por mucho que se retuerza... El fondo no cambia... Nada que hacer." Sus harapos están pegados a sus cuerpos y sus conciencias. Nada que hacer, sólo esperar que llegue el "salvador" que los visibilice... iy los salve! Hasta que llegue ese momento, sólo hay que permanecer siendo lo que el dominador quiere que seamos.

“¿Qué? ¿Nos vamos?” - pregunta Vladimir al final de la obra - “...Vamos” contesta Estragón. Y concluye el dramaturgo: (No se mueven).

Estamos ante lo que Cornelius Castoriadis denomina "la esencial inconvertibilidad del otro". Sobre todo proceso cultural de humanización cuelga 
la espada de Damocles de la tendencia humana a la estabilidad, al cierre de toda posibilidad de transformación, a la clausura - en términos de Castoriadis -del sentido que nos induce a otorgarle más importancia a la "voluntad de verdad" (de dogmas ciertos e inmutables que nos hacen creer que Godot está a punto de llegar) que a la "voluntad de poder" (de potencia humana de cambio y transformación que niega toda trascendencia y todo dogmatismo esencialista). Dado que en nuestra época - aunque algunos, como estamos viendo, se resistan a aceptarlo - se reconoce que los cambios culturales son producidos por el contacto con los otros, con los diferentes, con los que estructuran y perciben el mundo de un modo distinto y alternativo al nuestro, la estrategia de clausurar el sentido en una determinada configuración de verdades absolutas se dirige, sobre todo, a clausurar la posibilidad real de "convertibilidad" del otro en nosotros y viceversa.

Por un lado, se fijan determinados rasgos naturales y/o físicos que facilitan la identificación del otro como un ente no humano o como un ente inferior que se halla en fases previas de nuestra evolución como seres racionales: raza, rasgos físicos, "los harapos" de Beckett. Y, por otro, se les niega la capacidad de "movimiento", es decir, se les considera incapaces de convertirse en otra cosa diferente de lo que está implícito en sus rasgos inmutables: color, tipo de pelo, orígenes históricos, situación de pobreza o exclusión..., con lo que su pretendida "inmovilidad" nos facilitará, primero, la construcción del estereotipo generalizador (el buen esclavo negro, simplón, perezoso y pasivo; el pobre que no quiere salir de su pobreza por su pereza intelectual; el "moro" traicionero; el asiático sensual...), y, segundo, ofrece la coartada precisa para su colonización (la inferiorización natural del diferente, el mantenimiento y reproducción de las desigualdades...) sin contradicción alguna con el discurso de los derechos humanos (todos tenemos derechos por el mero hecho de ser seres ¿bumanos?).

Es el caso del discutido pero, asimismo, muy difundido libro de R. Herrnstein y C. Murray, The Bell Curve: Intelligence and Class Structure in American Life (1994). De un modo absolutamente claro y sin tapujos, los autores de este libelo racista, ${ }^{9}$ partiendo de una concepción restringida y etnocentrista

\footnotetext{
${ }_{9}$ Herrnstein y Murray mantenían estrechas relaciones con fundaciones de estatutos racistas como la Pioneer Fund o la Bradley Foundation. La "Pioneer Fund" fue fundada en 1937 en el círculo nazi alemán que promocionaba el apartheid y la aplicación de la eugenesia a los inmigrantes. Los autores del libro que comentamos citan con prolijidad a "intelectuales" racistas como Arthur Jensen, R.T. Osbourne, Richard Lynn y otros especialmente "interested in innocence for whites...Race differences show whites arent't at fault for blacks being down, and making whites pay for something they're not responsible for is a terrible injustice. Eliminating affirmative action is the first step. Next-please, yes, if only - eliminate the Civil Rights Act" (Herrnstein / Murray, 1994: 165). Ver Jacoby y Glauberman, 1995.
} 
de los coeficientes de inteligencia, ${ }^{10}$ afirman que los afro-americanos son genéticamente inferiores, tanto en capacidades como en habilidades, y que dicha característica, por el hecho de ser genética, es insuperable e inmutable. Su "morfología" (rasgos físicos y raciales) impide que tal inferioridad pueda cambiar en el futuro. Ahora bien, el objetivo de los autores no se queda en imputar únicamente determinados rasgos culturales esenciales a negros, mujeres, comunidades étnicas o de elección sexual diferente que impida su reconocimiento como seres humanos dotados de la misma capacidad para disfrutar de la vida y de los derechos, sino que se extiende a cuestiones políticas y económicas. A causa de esa "inmovilidad", de esa "esencialización" de determinados rasgos naturales, estos "intelectuales" continúan afirmando que quedan inmediatamente deslegitimadas todas las políticas públicas, sean educativas o laborales, que tiendan a implementar acciones afirmativas dirigidas a suplir políticamente los condicionamientos sociales que sufren negros, mujeres ${ }^{11}$, hispanos y, en general, todos los colectivos no blancos, no propietarios, no protestantes y patriarcales. La esencial inconvertibilidad del otro en alguien que pueda reconocerse como un igual no es un problema meramente cultural de reconocimiento de humanidad, sino tiene también que ver con cuestiones de redistribución de los bienes y de los derechos. Si negros, hispanos o mujeres comienzan a abandonar sus luchas materiales por recuperar sus posibilidades de acción culturales, políticas y económicas, se les va dejando el campo abonado a las ideologías racistas, absolutamente funcionales al neoliberalismo destructor de las prestaciones de la economía keynesiana, como las que estamos reseñando.

Esto no siempre fue así. A principios de los años setenta del siglo XX, y por poner sólo un ejemplo, la comunidad negra dio importantes pasos para el reconocimiento de su diferencia cultural (el orgullo negro, el black power) y, asimismo, para el reconocimiento de su estatus como ciudadanos de pleno derecho (la lucha por los civil rights) en el ejercicio de sus actividades econó-

\footnotetext{
${ }^{10}$ Estudios basados en Osbourne et al., 1978, y la revista de financiación y objetivos declaradamente racistas Mankind Quarterly (fundada por Robert Gayle un notorio racista anglosajón. Críticamente, Allen y Adams, 1992; y Betancourt y López, 1993.

${ }^{11} \mathrm{El}$ argumento racista de Herrnstein y Murray se extiende, como no podía ser menos, no sólo a las mujeres (Gustave Le Bon afirmó en 1897 que las mujeres eran "inevitablemente" menos inteligentes que los hombres debido a sus cerebros más pequeños: leamos lo que decía el mismo Le Bon: "All psychologists who have studied the intelligence of women, as well as poets and novelists (sic), recognize today that they represent the most inferior form of human evolution and that they are closer to children and savages than to an adult civilized man. They excel in fickleness, inconsistency, absence of thought and logic, and incapacity to reason. Without doubt there exist some distinguished women, very superior to the average man, but they are as exceptional as the birth of any monstruosity, as, for example, a gorilla with two heads; consequently, we may neglect them entirely” (apud Kriszner y Mandell, 1996. Ver asimismo, Keenan, 1996).
} 
micas, sociales y políticas. Por aquellos años, estaba más claro que hoy en día que los derechos individuales no "viven" en el vacío, sino que son la necesaria complementación de las luchas por los derechos sociales, económicos y culturales. Esto nos los muestra, incluso, la conservadora y racista industria hollywoodiense, la cual, al ver la fuerza de las reivindicaciones y las luchas continuas por el empoderamiento de los negros, supo, primero, aprovechar el campo abierto por los "nuevos" sujetos sociales y embolsarse cuantiosos beneficios con películas dirigidas a impulsar el empoderamiento negro. Pero, en un momento posterior, supo también encauzar tales demandas y tales acciones en beneficio de la ideología individualista, consumista y capitalista que siempre estuvo en la base de sus producciones. Así, y citando únicamente ejemplos de la industria cinematográfica, en 1973 salió al público la película Spook Who Sat By The Door, basada en la novela del mismo nombre de Sam Greenlee, en donde un negro consigue entrar, por primera vez, en las filas de la policía de elite norteamericana y usa sus conocimientos para entrenar a sus "colegas" en la rebelión contra la discriminación a la que son sometidos. Unos años antes, Ossie Davis dirigió su film Cotton Comes to Harlem, en donde dos detectives negros, dotados de los mismos indicadores de inteligencia que los tradicionales investigadores privados del cine negro holywoodiense, son capaces de ridiculizar los valores de los blancos y se permiten, incluso, ridiculizar a los propios negros que intentan engañar a su comunidad ofreciéndoles la posibilidad de viajar al "paraíso africano" y salir de su mísera situación. Ossie Davis inauguró lo que después se denominó los Blaxpoitations films, en los que, dada la fuerza y la vitalidad del movimiento negro de liberación, Hollywood reconoce una fuente de beneficios importante: filmes como Sweet Sweetback's Baadasss de Melvin Van Peebles o In the Heat of the Night de Norman Jewison, colocan a personajes negros que saben hacerse respetar por las autoridades blancas repletas de racismo y de prejuicios al estilo de The Bell Curve.

Desde el momento en que esas luchas por la dignidad de los negros dejan de tener relevancia y, como consecuencia, la comunidad negra pierde su capacidad de inquietar a las elites blancas, comienza a darse el ambiente necesario para nuevas formas de racismo y de exclusión. Ejemplo de ello lo encontramos en la película Car Wash, donde alrededor de un argumento que tiene que ver con la conquista del welfare para subsistir, se enfrentan dos personajes, uno $\mathrm{Abdul}^{12}$, el defensor y continuador del radicalismo de

\footnotetext{
${ }^{12}$ No es de extrañar que después de Malcolm X y la deriva musulmana de la comunidad negra, se le ponga al personaje fundamentalista de la película un típico nombre del mundo árabe. Ya se están sentando las bases para que culturalmente todo árabe, sea islámico o no, sea considerado un fundamentalista potencial. Por supuesto, que sigue habiendo excepciones a la tónica general de aban-
} 
los años sesenta y primeros setenta, y Lonnie ${ }^{13}$, la defensora de que el único camino que tienen los negros para salir de la miseria es la colaboración con sus jefes blancos y la aceptación ciega de los valores del individualismo y de la estrategia capitalista del beneficio personal, ajena, por supuesto, a toda lucha comunitaria o barrial. La obra, escrita por un blanco (Joel Schumacher), muestra el inicio de un camino de no retorno y de abandono de toda lucha social por el reconocimiento y la redistribución de recursos que empodere a la comunidad negra, la cual sobrevive como puede en las calles - o en las cárceles, habitadas fundamentalmente por negros - del país del capitalismo salvaje.

Esta cuesta abajo por la que se deslizan los movimientos sociales radicales de los sesenta y setenta y que está debilitando y desvaneciendo las reivindicaciones y las luchas sociales colectivas, permitirán que salgan y se divulguen libros como The Bell Curve y culminarán en la trágica sátira del negro "gracioso" que Spike Lee despliega, ya en el siglo XXI, en su película Bamboozled, donde los negros acaban pintados de negros - reduplicación de la comicidad y del estereotipo -, con el único objetivo de hacer reír a la mayor cantidad posible de audiencia televisiva.

Ya no se puede volver a los años cincuenta y a las políticas de "apartheid"; pero aún se producen filmes y se publican libros donde las actitudes radicales, antes elevadas a rango de heroicidad, se perciben como producto de fallos psicológicos o de genes estropeados inevitable y eternamente por la raza, la etnia o la sexualidad. La esencial inconvertibilidad del otro sólo se produce, pues, cuando ese otro, no tiene, o le han robado, lo que caracteriza la esencia de los derechos humanos de las personas: la capacidad para luchar

dono de la lucha por los derechos. Véase, por ejemplo, la película Beat Street de Harry Belafonte, en la que los jóvenes negros de los ghettos no les queda más futuro que la música y la danza para salir de sus situaciones (el hip hop como signo de rebeldía y protesta) o la serie televisiva (opuesta al cien por cien a las falacias consumistas y exitosas estilo Principe de Bel Air), llamada The Killing Floor, donde se muestran descarnadamente las dificultades que encuentran los trabajadores negros para fundar un sindicato en el Chicago de inicios de siglo XX. Pero son excepciones. Lo que abundan son ejemplificaciones, más o menos dulcificadas, de The Bell Curve. No olvidemos las peroratas individualistas, en las que ni se huelen las contradicciones sociales que mantienen a los negros en un escalón inferior de la escala social, de Richard Prior, o las, no tan inocentes, comedias de Eddie Murphy, como, por ejemplo, Beverly Hills Cop, donde aparece el idealizado mensaje de un mundo mejor, en el que los negros consigan por fin la aceptación de la ideología racista conservadora.

${ }_{13}$ Tampoco es de extrañar que el personaje que simboliza el entreguismo a la ideología capitalista, siempre enfrentada a las demandas comunitarias y de bienestar de los excluidos, sea una mujer. Hollywood, como barricada de las ideologías más conservadoras que sobrevuelan los USA, no ha dudado ni un instante en colocar a la mujer en el lugar que le corresponde como ser pasivo que depende absolutamente del hombre para salvarse de su destino de pobreza, marginación o peligros. Ver el magnífico trabajo de Michael Ryan y Douglas Kellner, Camera Politica. The Politics and Ideology of Contemporary Hollywood Film, (Ryan y Kellner, 1990), especialmente el capítulo "Politics of Sexuality", pp. 136-167. 
tanto por su reconocimiento cultural como por la redistribución de los recursos necesarios para vivir. Es decir, el racismo, la xenofobia y toda forma de discriminación hallan su terreno abonado cuando no existen condiciones para que todos y todas, especialmente los excluidos y marginados, puedan luchar por su particular concepción de la dignidad humana.

Aquí radica la grandeza de la denuncia radical que Beckett difumina por toda su obra. Sólo las condiciones que permitan luchar por la dignidad humana constituirán la única vía para que Estragón y Vladimir se muevan.

\section{Referencias Bibliográficas}

Allen, B.; Adams, J. (1992), "The Concept of 'Race': Let's Go Back to the Beginning”, Journal of Social Behaviour and Personality, 7, 163-168.

Arnaldez, Roger (1991), Trois messagers pour un seul Dieu. Paris: Albin Michel.

Benslama, Fethi (1998), "La répudiation originaire", Cabiers Intersignes, 13 (www. psychanalyse.refer.org/revue/intersignes/html; consultada en Mayo de 2003).

Bessis, Sophie (2002), Occidente y los otros: historia de una supremacia. Madrid: Alianza. Betancourt, H.; López, S.R. (1993), "The Study of Culture, Ethnicity, and Race in American Pychology", American Psychologist, 48, 629-637.

Cosby, Alfred (1986), Ecological Imperialism: The Biological Expansion of Europe, 900-1900. Cambridge: Cambridge UP.

Hamer, Mary (1989), "Putting Ireland on the Map", Textual Practice, 3(2), 184-201. Herrnstein, Richard J.; Murray, Charles (1994), The Bell Curve: Intelligence and Class Structure in American Life. New Cork: The Free Press.

Hufschmid, Eric (2002), Painful Questions: An Analysis of the September 11th Attack. Goleta, Ca.: Endpoint Software.

Keenan, Julian Paul (1996), "A Brief Analysis of ‘The Bell Curve”” (www.sfu.ca/ wwwpsyb/ issues/1996/winter/keenan.html).

Klein, Leon (2002), La gran mentira. ¿Y si Bin Laden no fuera culpable? La conspiración del petróleo. Barcelona: PYRE.

Kriszner, L.; Mandell, S. (1996), The Blair Reader. Upper Saddle River, NJ: Prentice Hall.

Jacoby, Russell; Glauberman, Naomi (orgs.), (1995), The Bell Curve Debate. New York: Random House.

Martín Muñoz, Gema (1999), El Estado Árabe. Crisis de legitimidad y contestación islamista. Barcelona: Bellaterra.

Martín Muñoz, Gema (2001), "¿'Supuesta confrontación Islam y Occidente o el problema de la supremacía occidental?”, Revista Internacional de Filosofía Política, 17, 101-114.

Martín Muñoz, Gema (2004), Multiculturalismo e islamofobia (http://www.mundoarabe. org/fobia1.htm; consultada en febrero de 2004). 
Meyssan, Thierry (2002), La gran impostura. Ningún avión se estrelló en el Pentágono. Madrid: La esfera de los libros.

Montell, Lluís Botinas i (2003), "Pero, ¿qué ocurrió en realidad el 11-S?”, El Viejo Topo, 183, 36-45.

Osbourne, R.; Noble, C.; Weyle N. (orgs.) (1978), Human Variation: The Byopsychology of Age, Race and Sex. New York: Academic Press.

Pryce-Jones, David (1988), The Closed Circle: an interpretation of the Arabs. New York: Harper \& Row.

Ryan Michael; Kellner, Douglas (1990), Camera Politica. The Politics and Ideology of Contemporary Hollywood Film. Bloomington: Indiana University Press.

Said, Edward (1996), Cultura e Imperialismo. Barcelona: Anagrama.

Smith, Neil (1984), Uneven Development: Nature, Capital and the Production of Space. Oxford: Blackwell. 